\title{
Isabelle Garnier-Mathez, L'épithète et la connivence. Écriture concertée chez les Évangéliques français (1523-1534)
}

\section{Dario Cecchetti}

\author{
(2) OpenEdition \\ Journals \\ Edizione digitale \\ URL: http://journals.openedition.org/studifrancesi/27371 \\ DOI: 10.4000/studifrancesi.27371 \\ ISSN: 2421-5856

\section{Editore} \\ Rosenberg \& Sellier
}

\section{Edizione cartacea}

Data di pubblicazione: 31 décembre 2006

Paginazione: 588-589

ISSN: 0039-2944

\section{Notizia bibliografica digitale}

Dario Cecchetti, «Isabelle Garnier-Mathez, L'épithète et la connivence. Écriture concertée chez les Évangéliques français (1523-1534) », Studi Francesi [Online], 150 (L | III) | 2006, online dal 30 novembre 2015, consultato il 08 novembre 2020. URL : http://journals.openedition.org/studifrancesi/27371 ; DOI : https://doi.org/10.4000/studifrancesi.27371

Questo documento è stato generato automaticamente il 8 novembre 2020.

\section{cc) (†) $\odot$}

Studi Francesi è distribuita con Licenza Creative Commons Attribuzione - Non commerciale - Non opere derivate 4.0 Internazionale. 


\title{
Isabelle Garnier-Mathez, L'épithète et la connivence. Écriture concertée chez les Évangéliques français (1523-1534)
}

\author{
Dario Cecchetti
}

\section{NOTIZIA}

ISABELLE GARNIER-MATHEZ, L'épithète et la connivence. Écriture concertée chez les Évangéliques français (1523-1534), Genève, Droz («Travaux d'Humanisme et Renaissance», $n^{\circ}$ CDIV), 2005, pp. 402.

1 L'A. illustra così, con estrema chiarezza, fin dalle prime righe della sua bella e interessante thèse, l'enjeu di questo lavoro: «La notion de connivence au sens moderne d' 'intelligence secrète' n'est pas étrangère à la génèse de notre travail, qui s'ingénie à unir dans une même réflexion deux domaines disjoints, ethnométhodologie et langue française de la Renaissance, à partir du questionnement de textes nés d'une nouvelle attitude face à la religion sous François $\mathrm{I}^{\mathrm{er}}{ }_{»}$ (p. 11). Tale questionnement de textes concerne il decennio che va dalla traduzione francese del Nuovo Testamento ad opera di Jacques Lefèvre d'Étaples (1523) all'affaire des Placards (1534), decennio che vede in azione il gruppo intellettuale ed ecclesiale indicato col termine di Évangéliques. L'A., consapevole che «la varietà, anzi la divergenza, delle interpretazioni riguardo l' Évangélisme ha finito col mascherarne l'unità se non addirittura la realtà storica», pur offrendo come premessa della sua indagine un quadro ragionato della storiografia concernente l'Évangélisme, ritiene che «la linguistica si riveli adatta ad apportare alla storia un contributo per una miglior conoscenza di questo periodo del regno di Francia e dell'espressione religiosa della lingua francese» (p. 341). Pertanto, sceglie venti testi di genere letterario differente, dalla poesia allo scritto prefatorio al trattato dottrinale, scalati nel decennio in questione e appartenenti ad autori punto di riferimento sociale 
come Marguerite de Navarre, a letterati di mestiere come Marot, a teologi come Lefèvre d'Étaples, a predicatori come Guillaume Farel o Aimé Meigret, ad autori, infine, costretti all'anonimato dalla censura - tutti comunque animati da interessi spirituali, teologici, filologici condivisi -, e questi testi sottopone anzitutto a un'indagine etnometodologica, un'indagine cioè che intende decrittare atti di linguaggio di un gruppo socioculturale dotato di una coerenza propria. Tale indagine ha lo scopo di elaborare «un lexique contextué, inteso come l'insieme di parole ed espressioni dotate di significati proprî, indicizzate all'universo di riferimento del gruppo studiato». L'A., «convinta dell'esistenza nel vocabolario di un gruppo socioculturale di segni reperibili che convogliano un senso nuovo, in décalage o in sovrapposizione rispetto al senso corrente, ha trasposto i procedimenti dell'etnometodologia a un campo diverso da quello della realtà quotidiana, oggetto di ricerca abituale della disciplina, e precisamente al campo dello scritto letterario. Infatti, nella misura in cui il linguaggio rappresenta il cuore della letteratura, e lo scritto, letterario o non, è un testimone accessibile trasmesso dalla storia, appare legittimo considerare un insieme di autori o di testi dei secoli precedenti alla stregua del village degli etnolinguisti, a patto che questi scritti presentino una coesione, vale a dire siano collegati da un obiettivo comune, sia pure d'ordine spirituale» (p. 14). Il gruppo coerente di autori, scelto da I. Garnier-Mathez, è quello degli Évangéliques che la critica designa come il circolo di Marguerite de Navarre, anche se postulare che gli autori évangéliques formino un village nella prospettiva etnolinguistica richiede una certa cautela. Cautela, peraltro, che l'A. pratica con grande maestria, data la sua forte preparazione storica e teologica, oltre che linguistica.

2 L'indagine sul corpus citato ha come base lo studio delle occorrenze degli aggettivi qualificativi nei testi in questione, nella convinzione che l'aggettivo non sia semplice manifestazione della soggettività di autori indipendenti, bensì «sia la parte visibile di un codice di comunicazione tra seguaci di una stessa ideologia religiosa, codice che lo porterebbe a funzionare come un linguaggio dentro il linguaggio, e in tal caso l'uso di precisi qualificativi rinvii a una logica di gruppo, una forma di espressione comunitaria, svelando i presupposti che rilevano sia dall'intenzione degli autori che dall'orizzonte d'attesa dei loro lettori o dei loro censori» (p. 16). Così, l'analisi del corpus arreca un utile contributo alla definizione e al chiarimento del vocabolario religioso impiegato negli anni 1520-1535 da autori considerati portatori - e per questo esaltati o condannati - di idee innovatrici, se non addirittura riformatrici.

3 In mancanza, fino ad oggi, di uno studio esauriente della teoria dell'aggettivo, per quanto riguarda la lingua francese del Cinquecento, l'A. si preoccupa anzitutto di precisare la posizione e il ruolo dell'aggettivo qualificativo nei trattati di grammatica e retorica del Rinascimento. In seconda istanza, vuole reperire nei testi del corpus quelle pratiche linguistiche ricorrenti di cui l'aggettivo qualificativo costituisce il nocciolo, seguendo un orientamento sia semantico sia stilistico: in tale prospettiva si isolano alcune espressioni chiave, quali vive foy, doctrine humaine, seul mediateur. In un'ultima sezione, l'A., «dopo la messa in valore del contributo essenziale dell'aggettivo qualificativo al senso del discorso évangélique, tiene conto del suo potenziale espressivo in ordine alla stilistica e alla retorica; ed elabora, secondo un principio di organizzazione essenzialmente debitore dell'amplificatio oratoria, una classificazione dei tipi di figure, in cui si illustrano i vocaboli ricorrenti nel corpus come pure gli aggettivi localmente pregnanti». 
4 Il lavoro di I. Garnier-Mattez è, a nostro avviso, profondamente innovatore e, a differenza di molte ricerche alla moda che si servono della sociolinguistica o di metodologie considerate d'avanguardia ma sono del tutto disancorate da una solida conoscenza storica (della storia delle idee, soprattutto), non è effimero ed offre strumenti validi di ricerca per il solido background storico, filologico, filosofico e teologico su cui è fondato. 